\title{
Tocilizumab for the treatment of systemic onset JIA: a single centre experience from India
}

\author{
Sujata Sawhney*, Manjari Aggarwal \\ From 2011 Pediatric Rheumatology Symposium sponsored by the American College of Rheumatology \\ Miami, FL, USA. 2-5 June 2011
}

\section{Purpose}

Systemic onset JIA (SJIA) is a common subcategory of JIA in India and often difficult to treat. Tocilizumab (Actemra), an IL 6 blocker has been shown to be effective in children with SJIA. The drug is available in India for over a year. We have a high burden of infectious diseases here and biologics are therefore used judiciously. We used the drug in SJIA patients to test the efficacy, tolerability and side effect profile.

\section{Methods}

Prospective study on the use of Tociluzimab in SJIA patients. Inclusion criteria: All children with SJIA more than three years of age who had persistent disease activity in spite of adequate NSAID, steroids and DMARDs for at least three months. Exclusion criteria: Presence of any active infection specifically tuberculosis.

\section{Results}

Time period of study: Children with SJIA were treated with Actemra from March 2009 to December 2010.The data was collected on standardized forms at institution of therapy, and then three monthly. Results up to one year follow up are presented. Demographic data: Twelve children were given Actemra, girls 4, boys 8 . The age range was from
4-19 years. The median age at disease onset was 8 years (range 1-14 years). The median time from disease onset to commencing Actemra was 6.1 years (range 1.3- 12.4 years). Infection screening: One child in this group had a positive PPD and Quantiferon Gold, where the Actemra was withheld till the child was given 6 months of anti-tubercular treatment. All children were tested for HIV, Hepatitis B and $\mathrm{C}$, none were positive.Background treatment for the patients: Methotrexate in 7, Leflunamide in one, Methotrexate and Leflunamide combination in 4. Eleven of the twelve were on oral steroids when Actemra was commenced. Infusion protocol and follow up: Patients received between one and eighteen doses and were given Actemra for one to eighteen months. The duration of follow up was from one to twenty three months. All patients were premedicated with hydrocortisone, ceterizine and paracetamol. No infusion reaction was noted in the total of 86 infusions given. Children over $20 \mathrm{~kg}$ were given $8 \mathrm{mg} / \mathrm{kg} / \mathrm{dose}$, those $<20 \mathrm{~kg}$ were given $12 \mathrm{mg} / \mathrm{kg} /$ dose. Most were given the infusion monthly.One child, who had had an episode of internuclear opthalmoplegia in the past developed a transient episode of diplopia 2 weeks after the first dose of Actemra, the drug was subsequently discontinued. Effect of Actemra: 1. Systemic features: nine children had fever at onset of therapy, two had fever at three months and no

Table 1

\begin{tabular}{|c|c|c|c|c|c|}
\hline Time point & Baseline & Three months & Six months & Nine months & Twelve months \\
\hline Mean $\mathrm{Hb}$ gm\% & 9.9 & 10.9 & 12 & 12.7 & 13.2 \\
\hline Mean ESR mm/hr & 48 & 23 & 14 & 10 & 07 \\
\hline Mean platelet $/ \mathrm{mm}^{3}$ & 471 & 319 & 253 & 230 & 215 \\
\hline MD global & 32 & 16 & 13 & 12 & 08 \\
\hline $\mathrm{CHAQ}$ & 1.2 & 1.05 & 0.95 & 0.625 & 0.625 \\
\hline Pts on pred & 11 & 09 & 05 & 02 & 02 \\
\hline
\end{tabular}

\footnotetext{
Sir Ganga Ram Hospital, New Delhi, India
} 
child had fever thereafter. 2. Arthritis: The mean joint count prior to Actemra was 5.16, 1.18 at three months and 0.2 at six and twelve months respectively. 3 . Serial changes in labs, MD global and CHAQ are tabulated.

\section{Conclusion}

With careful screening Tocilizumab can be used safely in areas that have a high burden of infections. The systemic features, haemoglobin and ESR respond rapidly, the arthritis responds later. Some children continue to have active disease inspite of this intervention.

\section{Disclosure}

Sujata Sawhney: None; Manjari Aggarwal: None.

Published: 13 July 2012

doi:10.1186/1546-0096-10-S1-A49

Cite this article as: Sawhney and Aggarwal: Tocilizumab for the

treatment of systemic onset JIA: a single centre experience from India.

Pediatric Rheumatology 2012 10(Suppl 1):A49.
Submit your next manuscript to BioMed Central and take full advantage of:

- Convenient online submission

- Thorough peer review

- No space constraints or color figure charges

- Immediate publication on acceptance

- Inclusion in PubMed, CAS, Scopus and Google Scholar

- Research which is freely available for redistribution

Submit your manuscript at www.biomedcentral.com/submit
() Biomed Central 